\title{
Impact of Co-Worker Support on Project Efficiency: Mediating Role of Team Cohesivenes
}

\author{
Maimoona Tariq* \\ Capital University of Science and Technology, Islamabad, Pakistan
}

\begin{abstract}
The Purpose of this study is to enhance the understanding of relationship between co-worker support, and project efficiency in the presence of mediating role of team cohesiveness and moderating role of Project culture. The context of this study is projects that are taking place in Pakistan. Data were collected from 100 participants, who participated in project as a team member, using structured questionnaire. Findings suggested that project efficiency is affected by co-coworker support in a positive manner, in the presence of team cohesiveness. Regression analysis for moderating and mediating variables was performed using Model 4 and 1 of the Process Macros for SPSS presented by Preacher and Hayes. It has been found that team cohesiveness mediates the relationship of co-worker support and project efficiency. Moreover, the project culture plays a moderating role on the relation of co-worker support and team cohesiveness. In the end the implications for project managers and future research are discussed.
\end{abstract}

\section{Introduction}

At the core of any project, there are individuals working hard to meet the efficiency levels of project. Project teams can be best positioned for achieving efficiency when they are created with the right mix of individuals (Bell and Brown, 2015). Co-worker support is the care and attention a worker receives from others for their wellbeing (Tews et al., 2013). Members of teams generally have choice in deciding whether or not they want to go beyond their level of duty to help others (Liang et al., 2015). Co-worker support either instrumental or emotional is seen to be more vital in younger team members (Poortvliet et al., 2015). Furthermore, supporting behavior among team members also enhances team cohesiveness (Stephens and Carmeli, 2016).

Team cohesion is the motivational force that sticks team members together. Cohesiveness in teams provides opportunities to learn social, technical, management and creative skills to increase project efficiency (Lindsjørn et al., 2016). Cohesive teams share potential benefits, which leave a positive impact on project goals (Knapp et al., 2015); whereas, project culture enhances team performance through improving skills, positive moods, motivation and communication (Bočková and Škoda, 2014). Moreover, project culture has a great influence on establishing workers cohesion to achieve project efficiency (Zuo et al., 2014).

Projects are built around teams to manage com-

*Corresponding author.

Email: maimoonatariq30@gmail.com

http://www.jbrc.pk plex goals effectively. Companies should create such a project environment which increases motivation of team members and abilities to engage in future teamwork (Stephens and Carmeli, 2016). In Projects, workers have closer relationships with their co-workers than with supervisors (Meng and Boyd, 2017); therefore, coworker support is generally related with positive outcomes; which means it is significant to set and maintain such a culture that effectively promotes supportive behaviors that lead to building high level of trust within teams for making teams more cohesive (Gountas et al., 2014).

Much research has been done on how co-worker support can encourage team cohesiveness (Bell and Brown, 2015).However, fewer studies have explored the specific impact that co-workers have in providing resources and support to successfully meet the demands of a complex Project environment (Halbesleben and Wheeler, 2015). The current study is based on the Projects performed under Pakistani context, since previous researches havent taken this region into account. The supportive behavior among team members can improve the cohesiveness of teams and thus, has been the focus of significant research attention (Knapp et al., 2015). Co-worker support has a different presence under different situations (Halbesleben and Wheeler, 2015); therefore, more research is required to determine situations which demand co-workers support (Meng and Boyd, 2017).

Research shows that there are some employees who 
do not require assistance. However, in case they are assisted, they manipulate it as if the person helping is trying to take credit (Scott et al., 2014). Therefore, it is necessary to highlight such factors that can build an acceptance of support among team members (Lynn et al., 2016). This study aims to make a contribution by identifying such aspects of Project culture which can create more chances of project success, specifically, in organizations which are relying more on teamwork (Liu and Cross, 2016). That is why it is essential to understand the nature of employees personal investment in supporting other employees (Cheruvelil et al., 2014).

\section{Literature Review}

\subsection{Relationship between Co-worker sup- port and Project efficiency}

Over the past few years, significant attention has been paid to enhancing supportive relationships among co-workers (Beehr et al., 2000). Co-worker support is the care and attention a worker receives from fellow workers for their wellbeing (Sloan, 2012). Studies have shown that support among coworkers can be of four primary types (Tafvelin et al., 2014); i.e. affective support which can be referred as emotional or esteem support, informational support which involves providing guidance and advice (Chen et al., 2014), Instrumental support by providing material assistance at the time of specific needs (Deelstra et al., 2003); whereas, social companionship is providing social assistance (Malecki and Demaray, 2003). Affective and companionship support are non-directive support as compared to directive functions of informational and instrumental support (Markham, 1998).

Project efficiency is meeting scope, budget and time goals of the project (Thylefors et al., 2005), which is measured at the completion of project by evaluating the output in terms of budget, time and cost (Shrnhur et al., 1997). The concept of project efficiency and effectiveness are commonly used for measuring different processes of projects (Atkinson, 1999). However, efficiency as compared to effectiveness is paid more attention to in project management literature (Sundqvist et al., 2014). Efficiency is referred as doing things the right way i.e. the level of high efficiency is achieved when whatever is completed, it is performed in the right way, free from defects and no waste of resources (Vitner et al., 2006). Efficiency meets all the internal requirements of project whether it is asset utilization, time management or meeting cost margins (Serrador and Turner, 2015).

Supportive relationships among workers in projects create a meaningful experience for them (Beersma et al., 2003); whereas, negative relations not only affect workers life but also decrease the chances of meeting project efficiency levels (Beehr et al., 2000). Coworker support bears direct influence on the social settings and workplace for employees. Helping behavior not only arises from personal affiliations but also from functional guidance of workgroup members (Zacher et al., 2014). Project performance if influenced by both instrumental and affective support, proved to be beneficial for driving both intrinsic and extrinsic rewards (Babin and Boles, 1996).

Several researches have shown a positive relation among coworkers support and performance (Carless and De Paola, 2000). Similarly, some have found satisfaction and performance at the highest levels among those employees whose social circles consisted of coworkers (Ducharme and Martin, 2000). Literature has shown a direct positive relationship between coworker support on workers wellbeing and increase project efficiency (Joiner, 2007). So, we conclude that:

H1: Co-worker support is positively associated with Project efficiency.

\subsection{Mediating role of Team cohesive- ness between Co-worker support and Project efficiency}

Team cohesion is the extent to which the members of the team are united and committed to each other for achieving project goals (Dionne et al., 2004).Team size, support from fellow workers, rewards for success and team accountability are such factors that contribute to team cohesiveness (Carless and De Paola, 2000). Team cohesiveness is the force that binds team members to corporate and work together for their mutual benefits (Chen et al., 2014). Corporation involves supporting and sharing the workload for achieving common goals. Cohesive teams are commonly referred to as having group spirit and team morale (Mathieu et al., 2015). Research has shown that cohesion is a group level phenomenon that is achieved by combined efforts of workers not only for their wellbeing but for the growth of entire team (Beal et al., 2003).

Team cohesiveness is highly influenced by helping behavior of workers which leads the team to greater communication and cooperation (Liang et al., 2015). When team members engage in such supporting behavior towards others, this will enhance team cohesiveness (Karasek et al., 1982). This evidence shows that team helping behavior is positively related to team cohesion. For instance, it enhances team members cooperation and willingness to share information and help others (Fruhen and Keith, 2014). Studies indicate that greater coworker support generates greater team communication and cohesiveness (Wei et al., 2014). Supporting behavior is also seen as a useful tool in generating high level of trust and information sharing among 
members of the team (Gillen et al., 2002). Cooperative behavior and team cohesiveness are thus the resulting outcomes of trust.

Helping behaviors are important contributors of team effectiveness and cohesiveness (Janz et al., 1997). Meanwhile, when team has more cooperation and trust, it enhances team performance which generates high project efficiency (Mach and Baruch, 2015). Team relations are greatly influenced by members perception and willingness to go beyond the job description. When team members willingly help other members of the team in completion of their job and provide mental support, it contributes to achieving goals (Toh and Srinivas, 2012).

A more cooperative team is more committed to their goals (Hoegl and Gemuenden, 2001). The beneficial effects of team cohesiveness come from aggregated cooperation and commitment of team members (Beersma et al., 2003). At the individual level, cohesion is related to job satisfaction and high performance whereas, at group level it is related with high efficiency levels (Belassi and Tukel, 1996). Cohesion is generally referred to positive outcomes (Wang et al., 2005); such as team performance, timely completion of work, team viability and meeting tough deadlines of the project. Therefore, we hypothesized:

H2: Team cohesiveness mediates the relationship between Co-worker support and Project efficiency.

\subsection{Moderating role of Project culture be- tween Co-worker support and team co- hesiveness}

Project culture is a combination of values, practices and assumptions that project members share with regard to specified behavior (Wiewiora et al., 2014). Research has shown that project culture has a significant impact on team bonding, supporting behavior, cooperation and effective performance (Aronson, 2015). However, implication of project culture in project management is far complex than in organization (Mach and Baruch, 2015). Because projects usually involve number of experts from various fields who have their own culture and norms of working. They usually face challenges in communicating with diverse nature of employees. (Cooper, 1994). These unique and diverse characteristics of team members make project culture critical to project based work (Mueller, 2014). However, strong project culture influences peoples knowledge sharing, communication and relations.

Various studies provide evidence that cultural values influence helping behaviors among coworkers by creating ways of interactions required for shaping support among team members (Klitmøller and Lauring, 2013). Characteristics of project culture involve em- ployee involvement programs and teamwork support. Its core values involve loyalty, commitment and participation of team members in order to achieve a common goal (Wang et al., 2005). Project culture acts as a contributor to healthy and supportive relationship among project teams (Fruhen and Keith, 2014). It also generates ways to increase knowledge sharing, providing emotional assistance and work support (Aronson, 2015).

In the presence of good culture, project employees are seen as more dependent upon coworkers for knowledge and support rather than supervisors and technology tools (Wiewiora et al., 2014). Culture exerts a positive influence on generating positive attitudes for helping coworkers (Salas et al., 2015). Workers in the presence of project culture think differently to be cooperative and supportive for resolving conflicts and satisfaction of other members. These behavioral changes come with the traits of a good project culture (Goodman et al., 2001).

Team cohesion is considered as the degree to which project team members transform into a single unit having common culture (Serrador and Turner, 2015). By developing a good project culture, workers are believed to have greater collective understanding and commitment towards project goals (Franz et al., 2016). Culture that promotes supportive behavior and rewards for support, creates high level of team cohesiveness compared to those cultures which do not promote such activities (Gu et al., 2014).

Studies have shown that culture is perceived as an indicator of better communication among diverse nature of employees and providing ways of exchanging information (Carless and De Paola, 2000). Teams that have high level of bonding and trust have high team cohesion. Research suggest that project culture helps in generating accessibility, good relations and team cohesiveness (Toivonen and Toivonen, 2014). Teams with high level of cohesiveness are considered as more effective performers. Meanwhile, team cohesion has a strong relation with the norms and values that the team shared as a part of common project culture (Gambi et al., 2015).

H3: Project culture moderates the relationship between Co-worker support and Team cohesiveness, so that the relationship is stronger in presence of project culture.

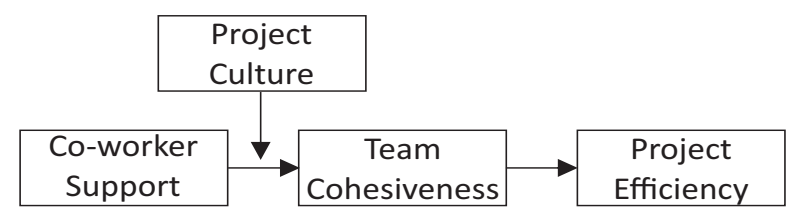

Figure 1: Framework 
Table 2.1: Means, Standard Deviations and Correlations

\begin{tabular}{cccccccc}
\hline & Variables & Mean & S.D & $\mathbf{1}$ & $\mathbf{2}$ & $\mathbf{3}$ & $\mathbf{4}$ \\
\hline $\mathbf{1}$ & CWS & 3.6933 & .69660 & $(.748)$ & & & \\
$\mathbf{2}$ & TC & 3.9525 & .81626 & $.383^{* *}$ & $(.758)$ & & \\
$\mathbf{3}$ & PC & 3.8763 & .68890 & $.257^{* *}$ & $.516^{*}$ & $(.794)$ & \\
$\mathbf{4}$ & PE & 3.5700 & 1.0843 & $.304^{* *}$ & .076 & $.262^{* *}$ & $(.897)$ \\
\hline$N=100^{* * *} p<0.001,{ }^{* *} p<0.01$, CWS is Coworker support, TC is Team cohesiveness, PC is project culture and PE is Project efficiency.
\end{tabular}

\section{Methodology}

\subsection{Population and Sampling}

The population for current study is workers who worked as a team in projects or who are a part of any team project. For this we have visited some universities and organizations and reach out to individuals who have played a role as a team members on any position in a project and asked few questions before giving them questionnaires to fill so that we can make sure that the sample is relevant and they are part of teamwork or at least they have performed teamwork in any project. The study setting was field study, and study did not manipulate the normal flow of work. It was done according to convenience of users. Convenient sampling technique was used in order to collect the data. The sample consists of $57 \%$ male and $43 \%$ female. Among them $79 \%$ individuals have $1-5$ years experience and 17\% have $6-10$ years experience; moreover, out of the respondents, $30 \%$ had education of bachelors, $40 \%$ Masters and 18\% MS/MPhil.

The primary data were collected through the help of structured questionnaire. Total 300 questionnaires were distributed to collect data, out of which 150 were received and 120 were useable, so the response rate was $50 \%$.

\subsection{Instruments}

The scale for Co-worker support consisted of 6 items such as My coworkers really care about my wellbeing and My Coworker care about my general satisfaction at work adapted from Mossholder et al. (2005). Respondents indicated the strength of agreement to these statements on a 5 point Likert scale whereby, 1 is equal to Completely false and 5 is equal to Completely true. Team Cohesiveness consisted of 4 items such as I feel that I am part of the team and My team works together better than most teams on which I have worked drawn from Jarvenpaa et al. (2004). Whereas, Project Culture is measured by 8 items such as The members of my team: Spent time discussing our teams purpose, goals, and expectations for the project and The members of my team: Talk enthusiastically about our teams progress derived from Carson et al. (2007).
While, Project efficiency was measured using a scale consisting of 6 items adapted from Gopal and Gosain (2010) using a five-point scale ( $1=$ Not at all, $5=$ Greater extent).

\section{Results}

The data were analyzed using regression analysis. First of all correlations and reliabilities were calculated to understand the relation between them. As shown in table 4.1.

Results were considered significant at $\mathrm{p}<0.01$. As shown in the table that Project efficiency, the dependent variable was significantly positively related to Coworker support ( $\mathrm{r}=0.383)$, project culture $(\mathrm{r}=.262)$. But was not correlated with Team cohesiveness $(\mathrm{r}=.076)$. Project culture the moderating variable is significantly positively related with coworker support $(\mathrm{r}=.257)$, team cohesiveness $(\mathrm{r}=.516)$. Meanwhile, team cohesiveness the mediating variable is positively related with Coworker support( $\mathrm{r}=.383)$.

Table 4.1: Regression Analysis

\begin{tabular}{lccc}
\hline Predictors & \multicolumn{3}{c}{ Project Efficiency } \\
& $\beta$ & $\mathbf{R}^{2}$ & $\Delta \mathbf{R}^{2}$ \\
\hline Step1 & & \\
Control Variables & 0.25 & \\
Step 2 & & \\
Coworker Support .526** & .134 & .109 \\
\hline${ }^{*} p<0.05 ;{ }^{* *} p<0.01$ & &
\end{tabular}

Regression analysis for Moderating and Mediating variables was performed using Model 4 and 1 of the Process Macro for SPSS presented by Preacher and Hayes (2008). The bootstrapping method generates indirect effect estimation, by including confidence interval of $95 \%$; whereas, a non-zero estimation shows that indirect effect is significantly different from zero at $\mathrm{p}<0.05$.

Regression analysis table for mediating variable presents direct effects, total effects of Team cohesive- 


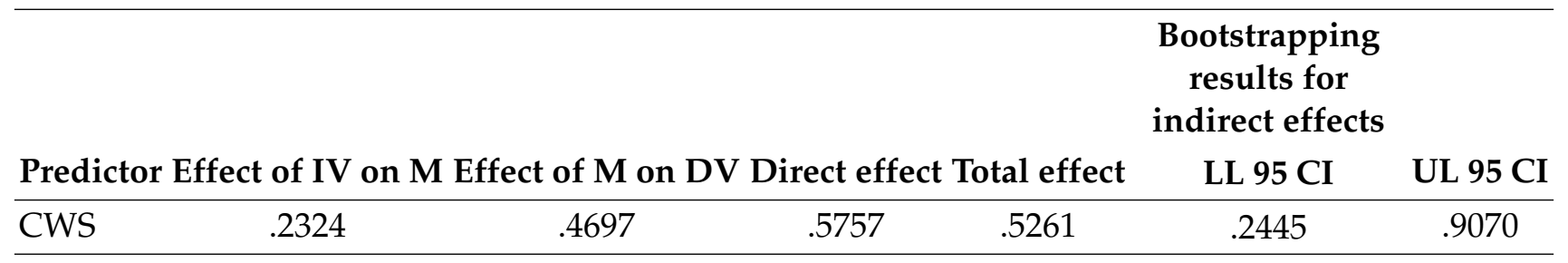

Note: LL=Lower limit, UL upper limit, $C I=$ Confidence interval, ${ }^{* *} p<0.001,{ }^{* *} p<0.01$

ness and Coworker support on Project efficiency also bootstrapping results for the indirect effects. The direct effects fell between 0.2231 and 0.9070 ; which shows that, zero was not present in the $95 \%$ confidence intervals, so the relationship of Coworker support and efficiency is mediated by team cohesiveness.

Table 4.3: Regression Moderation Analysis

\begin{tabular}{lccc}
\hline Predictors & $\Delta \mathbf{R}^{2}$ & $\mathbf{F}$ & $\mathbf{P}$ \\
\hline Coworker Support & .0430 & 6.5754 & .0120 \\
${ }^{*}$ Project Culture & & & \\
\hline${ }^{*} p<0.05 ;{ }^{* *} p<0.01$ & & &
\end{tabular}

The above table 4.4 shows the value of $\mathrm{F}, \mathrm{P}$ and change in R square. The $\mathrm{p}$ value .0120 is clearly showing the moderation effect.

As per the regression results, the first hypothesis was supported, i.e. Coworker support is positively and significantly associated with Project efficiency as $=.526$ and $\mathrm{p}<0.05$. Similarly, hypothesis two was also accepted which stated that team cohesiveness mediates the relationship between coworker support and project efficiency, as according to the results, zero was not present between 0.2231 and 0.8290 and $\mathrm{p}<0.05$. Ultimately, hypothesis three, i.e. Project culture moderates the relationship between Coworker support and team cohesiveness, so that the relationship is stronger in presence of project culture, found support as well at $\mathrm{p}=.0120$.

\section{Discussion}

Over the years, project teams have been receiving great importance because of their contribution and effectiveness in dealing with increased competition. The basic aim of this study was to enhance the understanding regarding, how coworker support is beneficial for achieving project efficiency. For this we developed a framework, with the help of which we concluded that coworker support somehow, plays a positive role in creating project efficiency. Supportive relationships among workers in projects create a meaningful experience for them. Helping behavior not only arises from personal affiliations but also from functional guidance of workgroup members. The results of the study have shown a direct positive relation of coworker support and increased project efficiency. So, project managers should be particular and more concerned about motivating workers for developing supportive behavior among them (Hoegl and Gemuenden, 2001).

Coworker support should also be rewarded by the managers in order to make it common in project teams (Bartol and Srivastava, 2002). In projects it is quite difficult to manage teams and make them committed to their work. However, first hypothesis of this study indicated that coworker support is positively associated with project efficiency and after its acceptance, it enhances the focus of project manager on coworker support.

In project teams, there is a strong relationship between cohesion and performance. Team cohesiveness is commonly referred to as the force that binds team members together to achieve a common goal. Whereas, team cohesiveness is a group level phenomenon which is achieved by combined efforts of team members. Results of the study have shown that when team members engage in supportive behavior it will enhance team cohesiveness, which leads to project efficiency. Team cohesiveness not only enhances team members cooperation but it also supports helping behavior among teams. Study has also indicated that greater coworker support generates greater team cohesiveness and project efficiency.

When teams have strong commitment they willingly help other members of the team in completion of their job for achieving project goals (Toh and Srinivas, 2012). At the individual level, cohesion is related to job satisfaction whereas, at group level it is related to high efficacy levels. Second hypothesis was about mediating role of Team cohesiveness on the relationship of coworker support and project efficiency. Meanwhile, the results have indicated that when project managers focus on team cohesiveness at the group level they can bring high level of project efficiency (Hoegl and Gemuenden, 2001).

It was hypothesized, that project culture strengthens the relation between coworker support and team 
cohesiveness. Because by developing a good project culture, workers are believed to have greater collective support and commitment towards project. Culture that promotes supporting behavior and reward for support creates high level of team cohesiveness compared to those cultures that do not promote such activities (Bočková and Škoda, 2014). If we look at the findings then there is a significant impact of project culture; whereas, implication of project culture in project management is far more complex than in organization.

Because projects usually involve number of experts from various fields who have their own culture and norms of working. They usually face challenges in communicating with diverse nature of employees. So, it might be considered that they develop their own perceptions and culture and dont care about project culture (Buvik and Tvedt, 2016). However, when project managers pay more attention towards project culture this makes team members more committed. With the acceptance of third hypothesis it is now clear that culture is such an indicator which brings better communication among diverse nature of employees and providing ways of exchanging information and support (Carless and De Paola, 2000). Teams that have high level of bonding and healthy relationships have high team cohesion.

\subsection{Limitations and Future Research}

Although the study provides some interesting findings regarding how project efficiency can be enhanced through coworker support in the presence of team cohesiveness; however, the study is subject to many limitations. First the data collected dont involve phases of project like initiation, planning, execution, control and closure. Project teams behave distinctively when the work proceeds through different phases of project life cycle. Early phases require more creative work whereas later phases demand technical work; we recognize that it is also possible that the different phases of the project may have different implications regarding the need for coworker support and level of team cohesion. Due to time limit we used convenient sampling technique, however, results would have been different if data were only collected from specific project team members. Another limitation is context of the study. This study was conducted within Pakistan as a specific context; therefore, research is required to determine how accurate the findings of this research are in other countries as well as in other industries like construction and R\&D.

Future directions may involve more studies on cohesion and efficiency in project team. We also acknowledge that there can be different alternative models for influence of team cohesiveness and commitment on the relationship between coworker support and project efficiency, so we recommend that future research should be designed to test the dynamic and causal relation- ship among coworker support, team cohesiveness and project efficiency. The goal of this study was to know, how the presence of team cohesiveness can impact the relationship between coworker support and project efficiency. And to fulfill this goal we tested our model in the same context. By considering the random sample of project team members, we derived considerable results. Meanwhile, different other variables can be used like in place of project efficiency project, effectiveness can also be measured. Knowledge sharing can be used as a mediator. Similarly project teams over time would be more challenging. In addition, future research can be done on the relationship between coworker support and project understanding like task familiarity to explain other project outcomes.

\subsection{Conclusion and Managerial Implica- tions}

Today one of the most important parts of project managers job is managing the project team who are performing the project tasks. Therefore, several practical implications can be drawn from this study for project managers. Findings suggest that the development of supporting relationships among team members should be motivated and encouraged. This will result in strong commitment towards the project. These positive relationships among team members can enhance coworker support within teams, which can lead to project efficiency. Our results show that we need to go beyond the prescribed job requirements and look forward to develop positive and strong sense of commitment to the team. Even though Team cohesiveness shows medium effect on building coworker support for contributing towards project efficiency, this does not mean that team commitment should be ignored.

It is important and without it coworker support is unlikely to occur. If team members have confidence in their fellow workers, their abilities and support they will be more willing to help them to make the project meet all efficiency levels. However, Support among team members needs to be developed within project team settings. This can be done by providing opportunities for team members to work together by helping each other and highlighting the importance of team member commitment and coworker support for reaching project goals. Project managers should introduce such ways that involve more coworker support other than supervisor support. So, that worker can get involved in helping other workers, which leaves a positive impact on project efficiency and can increase team cohesiveness. 


\section{References}

Aronson, Z. H. (2015). An investigation of the role of project culture in team efficacy and success in project-based work. International Journal of Innovation and Technology Management, 12(06):1550027.

Atkinson, R. (1999). Project management: cost, time and quality, two best guesses and a phenomenon, its time to accept other success criteria. International journal of project management, 17(6):337-342.

Babin, B. J. and Boles, J. S. (1996). The effects of perceived co-worker involvement and supervisor support on service provider role stress, performance and job satisfaction. Journal of retailing, 72(1):57-75.

Bartol, K. M. and Srivastava, A. (2002). Encouraging knowledge sharing: The role of organizational reward systems. Journal of Leadership \& Organizational Studies, 9(1):64-76.

Beal, D. J., Cohen, R. R., Burke, M. J., and McLendon, C. L. (2003). Cohesion and performance in groups: a metaanalytic clarification of construct relations. Journal of applied psychology, 88(6):989.

Beehr, T. A., Jex, S. M., Stacy, B. A., and Murray, M. A. (2000). Work stressors and coworker support as predictors of individual strain and job performance. Journal of Organizational Behavior, pages 391-405.

Beersma, B., Hollenbeck, J. R., Humphrey, S. E., Moon, H., Conlon, D. E., and Ilgen, D. R. (2003). Cooperation, competition, and team performance: Toward a contingency approach. Academy of Management Journal, 46(5):572-590.

Belassi, W. and Tukel, O. I. (1996). A new framework for determining critical success/failure factors in projects. International journal of project management, 14(3):141-151.

Bell, S. T. and Brown, S. G. (2015). Selecting and composing cohesive teams. In Team Cohesion: Advances in Psychological Theory, Methods and Practice, pages 181-209. Emerald Group Publishing Limited.

Bočková, K. H. and Škoda, M. (2014). Study of culture of project oriented society. International Journal of Information Technology and Business Management, 29(1).

Buvik, M. P. and Tvedt, S. D. (2016). The impact of commitment and climate strength on the relationship between trust and performance in cross-functional project teams: A moderated mediation analysis. Team Performance Management, 22(3/4):114-138.

Carless, S. A. and De Paola, C. (2000). The measurement of cohesion in work teams. Small group research, 31(1):71-88.

Carson, J. B., Tesluk, P. E., and Marrone, J. A. (2007). Shared leadership in teams: An investigation of antecedent conditions and performance. Academy of management Journal, 50(5):1217-1234.
Chen, F., Zhang, L., and Latimer, J. (2014). How much has my co-worker contributed? the impact of anonymity and feedback on social loafing in asynchronous virtual collaboration. International Journal of Information Management, 34(5):652-659.

Cheruvelil, K. S., Soranno, P. A., Weathers, K. C., Hanson, P. C., Goring, S. J., Filstrup, C. T., and Read, E. K. (2014). Creating and maintaining high-performing collaborative research teams: the importance of diversity and interpersonal skills. Frontiers in Ecology and the Environment, 12(1):31-38.

Cooper, R. B. (1994). The inertial impact of culture on it implementation. Information $\mathcal{E}$ Management, 27(1):17-31.

Deelstra, J. T., Peeters, M. C., Schaufeli, W. B., Stroebe, W., Zijlstra, F. R., and van Doornen, L. P. (2003). Receiving instrumental support at work: when help is not welcome. Journal of applied psychology, 88(2):324.

Dionne, S. D., Yammarino, F. J., Atwater, L. E., and Spangler, W. D. (2004). Transformational leadership and team performance. Journal of organizational change management, 17(2):177-193.

Ducharme, L. J. and Martin, J. K. (2000). Unrewarding work, coworker support, and job satisfaction: A test of the buffering hypothesis. Work and occupations, 27(2):223-243.

Franz, B., Leicht, R., Molenaar, K., and Messner, J. (2016). Impact of team integration and group cohesion on project delivery performance. Journal of construction engineering and management, 143(1):04016088.

Fruhen, L. S. and Keith, N. (2014). Team cohesion and error culture in risky work environments. Safety science, 65:2027.

Gambi, L. D. N., Boer, H., Gerolamo, M. C., Jørgensen, F., and Carpinetti, L. C. R. (2015). The relationship between organizational culture and quality techniques, and its impact on operational performance. International Journal of Operations \& Production Management, 35(10):1460-1484.

Gillen, M., Baltz, D., Gassel, M., Kirsch, L., and Vaccaro, D. (2002). Perceived safety climate, job demands, and coworker support among union and nonunion injured construction workers. Journal of safety research, 33(1):33-51.

Goodman, E. A., Zammuto, R. F., and Gifford, B. D. (2001). The competing values framework: Understanding the impact of organizational culture on the quality of work life. Organization Development Journal, 19(3):58.

Gopal, A. and Gosain, S. (2010). Research notethe role of organizational controls and boundary spanning in software development outsourcing: Implications for project performance. Information Systems Research, 21(4):960-982.

Gountas, S., Gountas, J., and Mavondo, F. T. (2014). Exploring the associations between standards for service delivery (organisational culture), co-worker support, self-efficacy, job satisfaction and customer orientation in the real estate industry. Australian Journal of Management, 39(1):107-126. 
Gu, V. C., Hoffman, J. J., Cao, Q., and Schniederjans, M. J. (2014). The effects of organizational culture and environmental pressures on it project performance: A moderation perspective. International Journal of Project Management, 32(7):1170-1181.

Halbesleben, J. R. and Wheeler, A. R. (2015). To invest or not? the role of coworker support and trust in daily reciprocal gain spirals of helping behavior. Journal of Management, 41(6):1628-1650.

Hoegl, M. and Gemuenden, H. G. (2001). Teamwork quality and the success of innovative projects: A theoretical concept and empirical evidence. Organization science, 12(4):435-449.

Janz, B. D., Colquitt, J. A., and Noe, R. A. (1997). Knowledge worker team effectiveness: The role of autonomy, interdependence, team development, and contextual support variables. Personnel psychology, 50(4):877-904.

Jarvenpaa, S. L., Shaw, T. R., and Staples, D. S. (2004). Toward contextualized theories of trust: The role of trust in global virtual teams. Information systems research, 15(3):250-267.

Joiner, T. A. (2007). Total quality management and performance: The role of organization support and co-worker support. International Journal of Quality $\mathcal{E}$ Reliability Management, 24(6):617-627.

Karasek, R. A., Triantis, K. P., and Chaudhry, S. S. (1982). Coworker and supervisor support as moderators of associations between task characteristics and mental strain. Journal of Organizational Behavior, 3(2):181-200.

Klitmøller, A. and Lauring, J. (2013). When global virtual teams share knowledge: Media richness, cultural difference and language commonality. Journal of World Business, 48(3):398-406.

Knapp, M. T., Breitenecker, R. J., and Khan, M. S. (2015). Achievement motivation diversity and entrepreneurial team performance: The mediating role of cohesion. European Journal of International Management, 9(5):593-613.

Liang, H.-Y., Shih, H.-A., and Chiang, Y.-H. (2015). Team diversity and team helping behavior: The mediating roles of team cooperation and team cohesion. European Management Journal, 33(1):48-59.

Lindsjørn, Y., Sjøberg, D. I., Dingsøyr, T., Bergersen, G. R., and Dyba, T. (2016). Teamwork quality and project success in software development: A survey of agile development teams. Journal of Systems and Software, 122:274-286.

Liu, W.-H. and Cross, J. A. (2016). A comprehensive model of project team technical performance. International Journal of Project Management, 34(7):1150-1166.

Lynn, G. S., Polat, V., and Reilly, R. R. (2016). Team trust and team learning in new product development projects. In Lets Get Engaged! Crossing the Threshold of Marketings Engagement Era, pages 639-640. Springer.
Mach, M. and Baruch, Y. (2015). Team performance in cross cultural project teams: The moderated mediation role of consensus, heterogeneity, faultlines and trust. Cross Cultural Management, 22(3):464-486.

Malecki, C. K. and Demaray, M. K. (2003). What type of support do they need? investigating student adjustment as related to emotional, informational, appraisal, and instrumental support. School psychology quarterly, 18(3):231.

Markham, S. K. (1998). A longitudinal examination of how champions influence others to support their projects. Journal of Product Innovation Management, 15(6):490-504.

Mathieu, J. E., Kukenberger, M. R., D'innocenzo, L., and Reilly, G. (2015). Modeling reciprocal team cohesionperformance relationships, as impacted by shared leadership and members competence. Journal of Applied Psychology, 100(3):713.

Meng, X. and Boyd, P. (2017). The role of the project manager in relationship management. International Journal of Project Management, 35(5):717-728.

Mossholder, K. W., Settoon, R. P., and Henagan, S. C. (2005). A relational perspective on turnover: Examining structural, attitudinal, and behavioral predictors. Academy of Management Journal, 48(4):607-618.

Mueller, J. (2014). A specific knowledge culture: Cultural antecedents for knowledge sharing between project teams. European Management Journal, 32(2):190-202.

Poortvliet, P. M., Anseel, F., and Theuwis, F. (2015). Masteryapproach and mastery-avoidance goals and their relation with exhaustion and engagement at work: The roles of emotional and instrumental support. Work $\mathcal{E}$ Stress, 29(2):150-170.

Preacher, K. J. and Hayes, A. F. (2008). Assessing mediation in communication research. The Sage sourcebook of advanced data analysis methods for communication research, pages 1354 .

Salas, E., Shuffler, M. L., Thayer, A. L., Bedwell, W. L., and Lazzara, E. H. (2015). Understanding and improving teamwork in organizations: A scientifically based practical guide. Human Resource Management, 54(4):599-622.

Scott, K. L., Zagenczyk, T. J., Schippers, M., Purvis, R. L., and Cruz, K. S. (2014). Co-worker exclusion and employee outcomes: An investigation of the moderating roles of perceived organizational and social support. Journal of Management Studies, 51(8):1235-1256.

Serrador, P. and Turner, R. (2015). The relationship between project success and project efficiency. Project Management Journal, 46(1):30-39.

Shrnhur, A. J., Levy, O., and Dvir, D. (1997). Mapping the dimensions of project success. Project management journal, 28(2):5-13.

Sloan, M. M. (2012). Unfair treatment in the workplace and worker well-being: The role of coworker support in a service work environment. Work and Occupations, 39(1):3-34. 
Stephens, J. P. and Carmeli, A. (2016). The positive effect of expressing negative emotions on knowledge creation capability and performance of project teams. International Journal of Project Management, 34(5):862-873.

Sundqvist, E., Backlund, F., and Chronéer, D. (2014). What is project efficiency and effectiveness? Procedia-Social and Behavioral Sciences, 119:278-287.

Tafvelin, S., Hyvönen, U., and Westerberg, K. (2014). Transformational leadership in the social work context: The importance of leader continuity and co-worker support. The British Journal of Social Work, 44(4):886-904.

Tews, M. J., Michel, J. W., and Ellingson, J. E. (2013). The impact of coworker support on employee turnover in the hospitality industry. Group $\mathcal{E}$ Organization Management, 38(5):630-653.

Thylefors, I., Persson, O., and Hellström, D. (2005). Team types, perceived efficiency and team climate in swedish cross-professional teamwork. Journal of interprofessional care, 19(2):102-114.

Toh, S. M. and Srinivas, E. S. (2012). Perceptions of task cohesiveness and organizational support increase trust and information sharing between host country nationals and expatriate coworkers in oman. Journal of World Business, 47(4):696-705.

Toivonen, A. and Toivonen, P. U. (2014). The transformative effect of top management governance choices on project team identity and relationship with the organizationan agency and stewardship approach. International Journal of Project Management, 32(8):1358-1370.

Vitner, G., Rozenes, S., and Spraggett, S. (2006). Using data envelope analysis to compare project efficiency in a multiproject environment. International Journal of project management, 24(4):323-329.

Wang, E., Chou, H.-W., and Jiang, J. (2005). The impacts of charismatic leadership style on team cohesiveness and overall performance during erp implementation. International Journal of Project Management, 23(3):173-180.

Wei, K., Crowston, K., Li, N. L., and Heckman, R. (2014). Understanding group maintenance behavior in free/libre open-source software projects: the case of fire and gaim. Information $\mathcal{E}$ Management, 51(3):297-309.

Wiewiora, A., Murphy, G., Trigunarsyah, B., and Brown, K. (2014). Interactions between organizational culture, trustworthiness, and mechanisms for inter-project knowledge sharing. Project Management Journal, 45(2):48-65.

Zacher, H., Jimmieson, N. L., and Bordia, P. (2014). Time pressure and coworker support mediate the curvilinear relationship between age and occupational well-being. Journal of occupational health psychology, 19(4):462.

Zuo, J., Zillante, G., Zhao, Z.-Y., and Xia, B. (2014). Does project culture matter? a comparative study of two major hospital projects. Facilities, 32(13/14):801-824. 